\title{
CARACTERIZACIÓN PARCIAL DEL VENENO DE LA SERPIENTE CASCABEL PERUANA Crotalus durissus terrificus
}

\section{PARTIAL CHARACTERIZATION OF THE VENOM OF THE PERUVIAN RATTLESNAKE Crotalus durissus terrificus}

\author{
César Remuzgo, Miryam Paola Alvarez, Fanny Lazo y Armando Yarlequé *
}

\section{RESUMEN}

Se ha investigado el contenido proteico y algunas actividades enzimáticas del veneno de la serpiente cascabel Crotalus durissus terrificus procedente de la región de Sandia, Puno; para ello se empleó el veneno total así como las fracciones obtenidas mediante cromatogralia de filtración en Sephadex G-100. El porcentaje de proteina calculado por el método de Lowry fue de $68,6 \%$ para el veneno total; habiéndose obtenido 3 picos de proteina durante el fraccionamiento; en el primero se registró actividad proteolítica, en el segundo, las actividades amidolítica, coagulante y fosfolipasa $A_{2}$. mientras que en el tercero se detectó otra fracción proteolítica. No se registró la actividad acetilcolinesterasa mientras que la actividad $\mathrm{L}$-aminoácido oxidasa sólo se encontró en el veneno total.

Palabras clave: Veneno, serpiente cascabel, enzimas, Puno

\begin{abstract}
The venom of the rattlesnake Crotalus durissus terrificus from the region of Sandia, Puno, has been investigated for its protein content and some enzymatic activities, using for th the whole venom as well as the fractions obtained by gel filtration chromatography in Sephadex G-100. The protein percentage calculated by the method of Lowry was of $68,6 \%$ for the whole venom; 3 peaks were obtained during the fractionation; the first showed proteolytic activity, the second, amidolytic, clotting and phospholipase $A_{2}$ activities, while the third, another proteolytic activity. Acetylcholinesterase activity was not found while L-amino acid oxidase activity was found only in the whole venom.
\end{abstract}

Keywords: Venom, rattlesnake, enzymes, Puno.

\section{INTRODUCCIÓN}

La serpiente cascabel sudamericana Crotalus durissus terrificus pertonece a la subfamilia Crotalinae y es considerada la más peligrosa de las especies de este grupo en América. Se trata de un reptil corpulento que mide hasta $1,8 \mathrm{~m}$ y en el Perú está restringida a la provincia de Sandia, departamento de Puno (Meneses, 1974; Carrillo e Icochea, 1995). Debido a los numerosos accidentes reportados tanto en Norteamérica como en Brasil, se ha

Laboratorio de Biología Molecular. ICBAR. Facuitad de Ciencias Biclógicas Unversidad Nacionai Mayor de San Marcos.

Emall d190061 în unmsm edupe investigado ampliamente su veneno y se ha encontrado manifestaciones clinicas muy severas que van desde la coagulación sànguínea e hipotensión hasta transtornos renales y neurotoxicidad; este último efecto escl responsable de la muerte (Russcll, 1983).

En 1938 se aisló una neurotoxina de este veneno, que fuc denominada crotoxina (Slotta y Fraenkel-Conrat, 1938-39). la cual se demostró posteriormente que estaba compuesta por una potente fosfolipasa $A_{2} y$ un péptido ácido asociado. Más adelante se han purificado otras neurotoxinas como la crotamina (Gonçalves, 1956), convulxina 
(Prado-Franceschi y Brazil, 1981) y giroxina (Barrio, 1961); esta última es asociada a la enzima similar a trombina (Alexander et al., 1988).

Una observación interesante es la existencia de variaciones en la composición del veneno de una misma especie debido a diferencias geográficas, estación del año en que se colecta el veneno, edad de la serpiente y la dieta (Minton and Weinstein, 1986). Asimismo se ha encontrado que $C$. durissus terrificus de algunas regiones geográficas en Sudamérica sólo producen descenso de la presión sanguínea (Vellard y Huidobro, 1942).

Comoes sabido, el ofidismo es un problema de salud que aflige principalmente a los pobladores de las zonas de selva y en el Perú, donde las serpientes venenosas corresponden a 33 especies algunas de las cuales se ubican en los valles interandinos y la costa (Carrilloe Icochea, 1995). Sin embargo, C. durissus terrificus sólo ha sido encontrada en la zona de Sandia y no se tiene mayor información sobre la composición de su veneno y sus efectos biológicos. Los estudios realizados por Cárdenas et al., 1995 con especímenes en cautiverio han permitido establecer la existencia de varias actividades enzimáticas con el propósito de establecer los principales factores que determinan el envenenamiento.

\section{MATERIAL Y MÉTODOS}

\section{MATERIAL BIOLÓGICO}

Se utilizó veneno de la serpiente cascabel C. durissus terrificus, colectado de dos especímenes procedentes de la provincia de Sandia (Puno), al sureste del Perú y mantenidos en cautiverio en el Serpentario "Oswaldo Meneses"del Museo de Historia Natural de la Universidad Nacional Mayor de San Marcos. El veneno extraído y liofilizado fue almacenado a $-8^{\circ} \mathrm{C}$.

\section{REACTIVOS}

Se utilizó Sephadex G-100, albúmina sérica bovina, L-leucina, o-dianisidina, peroxidasa de rabanito, Joduro de acetiltiocolina, 4, 4' ditiodipiridina, Na-Benzoil-DL-Arginina-pnitroanilida (BApNA), fibrinógeno bovino y caseína, los cuales fueron obtenidos de Sigma Chemical Company (St. Louis, USA). Los demás reactivos químicos usados fueron de grado analítico.

\section{DETERMINACIÓN DE PROTEÍNAS}

Se utilizó el método de Lowry (1951) y durante el fraccionamiento se midió la concentración de proteínas a $280 \mathrm{~nm}$, usando como patrón a la albúmina sérica bovina.

\section{FRACCIONAMIENTO CROMATOGRÁFICO}

Se aplicó $38 \mathrm{mg}$ de veneno liofilizado disuelto en $1 \mathrm{~mL}$ de buffer acetato de amonio $0,1 \mathrm{M}$ pH 6,0 a una columna de Sephadex G$100(38,5 \times 1,1 \mathrm{~cm})$ eluida con el mismo buffer a una velocidad de flujo de $8,7 \mathrm{~mL} / \mathrm{h}$, colectándose fracciones de $2 \mathrm{~mL}$.

\section{ACTTVMADES ENZMMÁTICAS}

\section{L-aminoácido oxidasa}

Se determinó por el método descrito en el Worthington Enzyme Manual (Worthington Biochemical Corporation, 1977). La mezcla de reacción contenía: L-leucina $0,1 \%$ y odianisidina $0,0065 \%$ y peroxidasa de rabanito $0,005 \%$ en buffer Tris $\mathrm{HCl} 0,2 \mathrm{M}$ pH 7,5; además de la fracción enzimática o el veneno total.

La actividad se determinó por el incremento de la absorbancia a $436 \mathrm{~nm}$.

\section{Acetilcolinesterasa}

Fue evaluada por el método de Ellman et al. (1961). Para ello se empleó como substrato Ioduro de acetiltiocolina $25 \mathrm{mM}, 4,4^{\prime}$ ditiodipiridina 1,25 $\mathrm{mM}$ en buffer fosfato 0,05 $\mathrm{M} \mathrm{pH} \mathrm{7,4.} \mathrm{Al} \mathrm{adicionarse} \mathrm{la} \mathrm{alícuota} \mathrm{de} \mathrm{veneno}$ 
o la fracción correspondiente se midió el incremento de absorbancia a $324 \mathrm{~nm}$.

\section{Fosfolipasa $\mathrm{A}_{2}$}

Se emoleó solución lipoproteica (yema de huevo) al . $5 \%$ en buffer Tris $\mathrm{HCl} 10 \mathrm{mM}$ con $\mathrm{CaCl}_{2} 10 \mathrm{mM}$ a pH 7,5, midiéndose el retardo en el tiempo de coagulación luego de 15 minutos de incubación con la fracción o el veneno crudo (Viáal y Stoppani, 1971).

\section{Amidolítica}

Se utilizó el substrato cromogénico $\mathrm{Na}$ Benzoil-DL-Arginina-p-nitroanilida (BApNA) $9 \times 10^{-4} \mathrm{Ml}$ en buffer Tris $\mathrm{HCl} \mathrm{0,1} \mathrm{M} \mathrm{pH} \mathrm{8,1,}$ midiéndose la aparición del color amarillo a $405 \mathrm{~nm}$ luego de agregar la fracción o veneno (Erlanger et al., 196I).

\section{Coagulante}

Fue determinada usando $0,2 \mathrm{~mL}$ de fibrinógeno bovino $5 \mathrm{mg} / \mathrm{mL}$ en buffer fosfato salino 0,02 M pH 7,2, se agregó luego 0,1 mL de veneno o fracción; registrándose el tiempo de coagulación en segundos (Copley et al., 1973).

Tabla 1. Actividades enzimáticas presentes en el veneno de la serpiente cascabel peruana Crotalus durissus terrificus y sus fracciones

\section{Proteolítica}

La actividad proteolítica se determinó según el método de Kunitz, modificado por Takahashi y Ohsaka (1970), empleando caseína al 2\% en buffer Tris $\mathrm{HCl} 0,2 \mathrm{M} \mathrm{pH} \mathrm{8,5.} \mathrm{Luego} \mathrm{de}$ agregar la fracción o veneno correspondiente, se midió la aparición de productos ácidos solubles a $280 \mathrm{~nm}$.

\section{ELECTROFORESIS}

Los picos obtenidos fueron analizados por electroforesis en gel de poliacrilamida con dodecil sulfato de sodio (SDS-PAGE) en condiciones no reductoras (Laemmli, 1970), utilizandr como proteímas patrones albúmina bovina (66 kDa), ovoalbúmina $(45 \mathrm{kDa})$ y lisozima (14,3 kDa). Las muestras se corrieron en un gel de resolución al $9.5 \%$ por una hora a 100 voltios. El gel fue teñido con azul brillante de Coomassie $0,1 \%$.

\section{RESULTADOS Y DISCUSIÓN}

El contenido de proteínas del veneno total de C. durissus terrificus fue del 68.6\%. Este porcentaje es similar al encontrado en otras

\section{ACTIVIDAD ESPECÍfICA (Unidades/mg proteína)}

\begin{tabular}{|c|c|c|c|c|}
\hline \multirow[b]{2}{*}{ Actividades enzimáticas } & \\
\hline & Veneno & Pico 1 & Pico 2 & Pico 3 \\
\hline L-aminoácido oxic' sai" & 3,591 & - & - & - \\
\hline Fosfolipasa $A_{2}{ }^{n}$ & 3,141 & - & 6,26 & - \\
\hline Amidolítica" & 0,02 & - & 0,102 & - \\
\hline Coagulante $^{J}$ & 0,17 & - & 0,499 & - \\
\hline Proteolítica ${ }^{\mathrm{c}}$ & 4,394 & 26,07 & - & 8,51 \\
\hline Acetilcolinesterasa' & - & - & - & - \\
\hline
\end{tabular}

"I unidad = nmoles de L--leucina oxidadus por minuto

"I unidad = liempo de retardo en la coagulación por minuto

- I unidad = umoles de p-nitroanilida liberados por minuto

"I unidad = inversa del tiempo de coagulación

- I unidad = $\mu g$ de L-tirosina liberados por minuto

'I unidad $=\mu$ moles de acetiltiocolina hidrolizados por minuto 
serpientes peruanas de la subfamilia Crotalinae como Bothrops pictus $(63,8 \%)$ y Bothrops atrox (69,2\%) (Cárdenas, 1995); sin embargo, posee un menor porcentajc con respecto a $C$. durissus terrificus de Argentina $(81,4 \%$ ) y de Brasil (76,9\%) (Yarlequé, 1987; Cárdenas, 1995).

Las actividades enzimáticas del veneno de C. durissus terrificus son mostradas en la Tabla 1; no se detectó, como puede observarse, la presencia de acetilcolinesterasa en las fracciones y el veneno crudo.

Hemos encontrado una baja actividad Laminoácido oxidasa. Este resultado es coincidente con lo reportado para el veneno de $C$. durissus terrificus de Brasil y Argentina (Tan and Ponnudurai, 1992; Vidal et al, 1972). La enzima L-aminoácido oxidasa se encuentra presente en pequeñas cantidades en el veneno, ya que éste era de color blanco, y como es sabido posee como grupo prostético al FAD el cual le da la coloración amarilla a los venenos. Sin embargo, a veces esta serpiente puede producir veneno de color amarillo y otras veces de color blanco (Vidal et al., 1972). La acción biológica de esta enzima en el veneno no está determinada, aunque recientemente se ha reportado que posee una acción antibacteriana y posiblemente sea parte del mecanismo de protección (Yarlequé et al., 1997).

Por otro lado, los venenos que presentan alta actividad proteolítica se caracterizan por producir hemorragías, necrosis y severa lisis de las proteínas de los músculos; así los venenos crotálidos son más proteolíticos que los vipéridos y éstos que los elápidos. El veneno de $C$. durissus terrificus siendo un crotálido es poco proteolítico (Otero et al., 1992), lo que concuerda con nuestros resultados y los hallados para ponzoñas de esta especie de Argentina y de Brasil (Yarlequé, 1987 ; Cárdenas, 1995).
Igualmente La actividad fosfolipasa $A_{2}$ encontrada en este veneno es baja con respecto al veneno de otros crotálidos y de venenos de elápidos (Cárdenas, 1995); resultado similar fue reportado por Tan and Ponnudurai (1992). La presencia de esta actividad en el veneno es asociada al complejo crotoxina, lo que explica la nefrotoxicidad, la hemolisis intravascular por alteraciones en la membrana eritrocítica producidas por fosfolipasas de acción indirecta y el shock neurotóxico producidos aurante el envenenamiento (Brazil, 1966).

En cuanto a la actividad coagulante, ésta es usualmente debida a la enzima similar a trombina, la que se caracteriza por poseer también aclividad amidolítica y estar relacionada con la manifestación del síndrome giroxina en animales inyectados, donde se producen episodios temporarios caracterizados por opistotonos y rotaciones alrededor del aje axial (Alexander et al., 1988; Barrio, 1961). Su presencia explica los transtornos en la coagulación que se dan durante el envélienamiento (Russell, 1983).

El fraccionamiınto cromatográfico del veneno crudo sobre una columna de Sephadex G-100 ha mostrado tres picos de proteína (ligura 1). En el primer pico y en el tercero encontramos la presencia de actividad proteolítica; la del primer pico es más activa que la del tercer pico. En el segundo pico encontramos la presencia de actividad amidolítica, coagulante y fosfolipasa $A_{2}$. No se pudo registrar la actividad L-aminoácido oxidasa (Tabla I), algunos autores sugieren una progresiva inaclivación de la enzima de $\mathrm{pH}$ 5,5 a 7,5 en el veneno de Crotalus adamanteus (Coles et al., 1980); sin embargo en nuestro caso esta siluación aún no ha sido explorada.

$\mathrm{El}$ análisis electroforético en condiciones denaturantes de los picos obtenidos nos mostró un pimer pico con la presencia de proteínas 


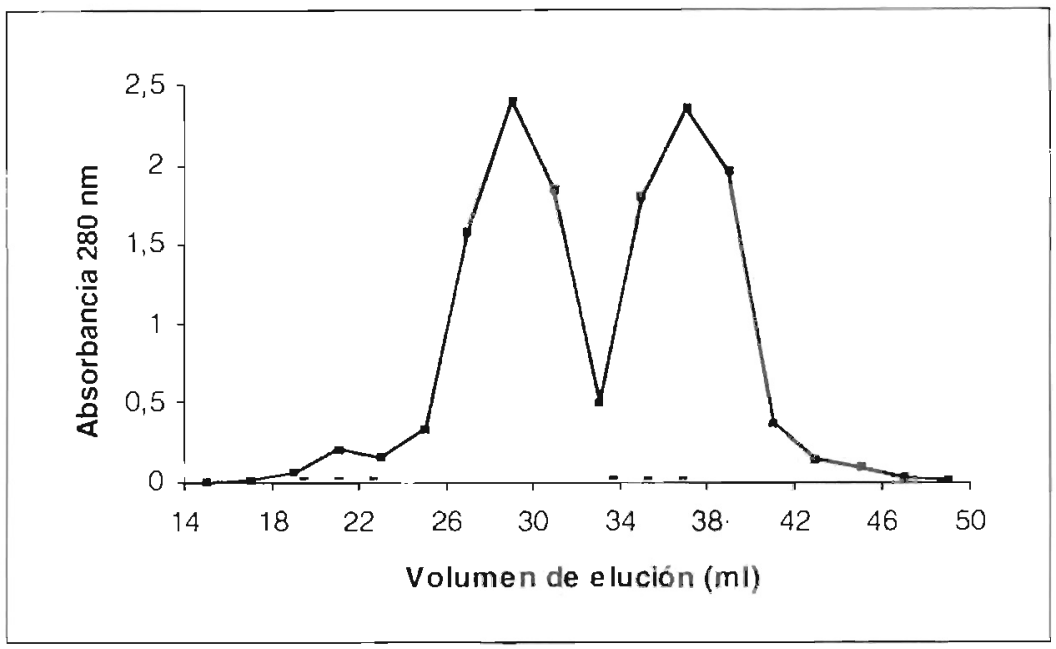

Figura 1: Cromatografía de filtración en gel sobre Sephadex G-100 del veneno de Crotalus durissus terrificus. (- - -) Actividad proteolítica

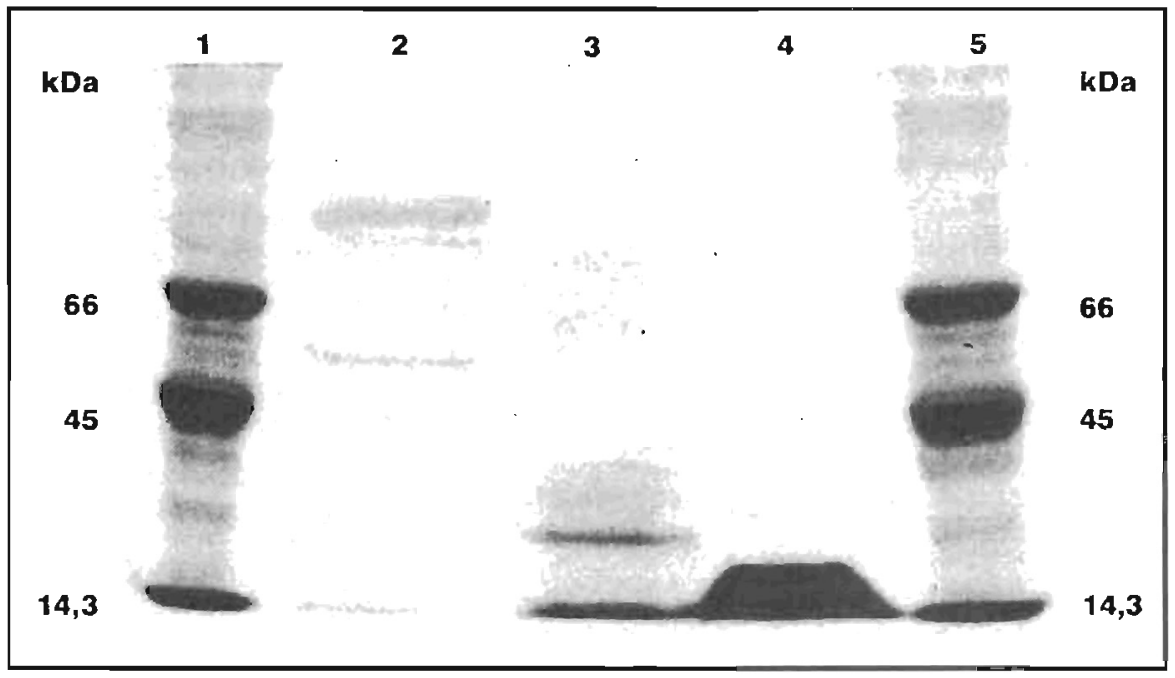

Figura 2: Electroforesis en gel de poliacrilamida en presencia de dodecil sulfato de sodio. Se utilizó un gel de resolución al 9,5\%.

1 y 5: Marcadores de peso molecular
2: Pico 1
3: $\operatorname{Pico} 2$
4: Pico 3

que migran en un rango de peso molecular de 54,2 a $103,3 \mathrm{kDa}$ aproximadamente; el segundo pico mostró dos bandas de proteína con pesos moleculares aproximados de 22,5 y 14,8 kDa, $y$ el tercer pico una prominente banda con proteínas con pesos moleculares posiblemente menores a $15 \mathrm{kDa}$ (Figura 2). Aun cuando los electroferogramas nos han permitido una evaluación inicial del número de bandas proteicas en este veneno, es necesario variar algunas condiciones como, por ejemplo, aumentar el porcentaje de acrilamida para obtener una mayor resolución de dichas bandas. 
Una exploración más detallada de este veneno nos permitirá elucidar la acción biológica de sus componentes proteicos y su toxicidad en humanos; $y$, por otro lado, entender por qué esta especie se desarrolla en un hábitat tan estrecho y definido como la selva sudeste de nuestro país, teniendo en cuenta su amplia distribución en la selva de Brasil, Argentina y Bolivia.

\section{LITERATURA CITADA}

Alexander, G.; Grothusen, J.; Zepeda, H. and Schwartzman, R.J. 1988. Gyroxin, a toxin from the venom of Crotalus durissus terrificus, is a thrombin-like enzyme. Toxicon 26, 953-960.

Barrio, A. 1961. Gyroxin, a new neurotoxin of Crotalus durissus terrificus venom. Acta. Physiol. Latinoamericana 11, 224.

Brazil, O. V. 1966. Pharmacology of crystalline crotoxin. II. Neuromuscular blocking action. Mem. Inst. Butantan 33, 981 992.

Cárdenas, J.; Pantigoso, C., Málaga, O. y Yarlequé, A. 1995. Contenido proteico y algunas actividades enzimáticas en tres venenos de serpientes mantenidas en cautiverio. Boletin de la Sociedad Química del Perú. N. ${ }^{\circ}$ 3, Vol. LXI N. ${ }^{\circ}$ $3,151-163$.

Carrillo, N. and ICOCHEA, J. 1995. Lista taxonómica preliminar de los reptiles vivientes del Perú. Publ. Mus. Hist. Nat. UNMSM (A) 49, 1-27.

Coles, C.; Edmondson, O. \& Singer, T. 1980. Mechanism of the reversible activationdesactivation of L-aminoacid oxidase. Flavins and Flavoproteins. Tokio, Japan Scientific Press, 101-105.
Copley, A., Benerjee, S. and Devi, A. 1973. Studies of snake venoms on blood coagulation. I. The thrombo serpentin (thrombin like) enzyme in the venoms. Thrombos. Res. 2, 487.

Ellman, C. Z.; Courney, K. D.; Andrés, V. and Featherstone, R.M. 1961. A rapid method for the stimation of acetylcholinesterase, Biochem. Pharmac. 7, 88-95.

Erlanger, B.; Kokowsky, N. and Cohen, W. 1961. The preparation and properties of two new chromogenic substrates of trypsin. Arch. Biochem. Biophys 95, 271-278

Gonçalves, J. M. 1956. Purification and properties of crotamine. In Venoms, eds. E. E. Buckley and N. Porges, pp. 261-273.

Laemmli, U. K. 1970. Cleavage of structural proteins during the assembly of the head of bacteriophage $\mathrm{T}_{4}$ Nature 227,680 685.

Lowry, O. H.; Rosebrough, N.; Farr, A. and Randall, R. 195I. Protein measurement with the folin phenol reagent. J. biol. Chem 193, 265-275.

Meneses, O. 1974. Los animales venenosos y sus peligros. Instituto de Salud Pública, Lima- Perú. Publicación N. ${ }^{\circ}$, pp. 314.

Minton, S. A. and Weinstein, S.A. 1986. Geographic and ontogenic variation in venom of the western diamonback rattlesnake (Crotalus atrox). Toxicon 24, 7l-80.

Otero, R.; Osorio, R.G.; Valderrama, R. and Giraldo, C. A. 1992. Efectos farmacológicos y enzimáticos de los venenos de serpientes de Antioquía y Choco (Colombia). Toxicon 30,611620 . 
Prado-Franceschi, J. and Brazil, O. V. 1981. Convulxin, a new toxin from tha venom of the South American rattlesnake Crotalus durissus terrificus. Toxicon 19, 875-887.

Russell, F. E. (1983) Snake venom poisoning. Scholium International, Inc. New York - USA., pp. 369.

Slotta, C. H. \& Fracıkєє ${ }_{1}$ Conrat, H.L. 1938 39. Estudos quimicos sobre os venenos ofidicos. Purificação e cristalização do veneno da cobra Cascavel. Mem. Inst. Butantan 12, 505-513.

Takahashi, T. and Oohsaka, A. 1970. Purification and characterization of a proteinase in the venom of Tri eresurus flavoviridis. Complete separation of the enzyme from hemorrhagic activity. Bicchim. biophys. Acta 198, 293-307.

Tan, N. H. and Ponnudurai, G. 1992 Biochemical characterization of snake venoms. In Recent advances in toxinology research, Vol. 1, pp. 210-258 (Gopalakrishnakone, P and Tan, C.K. Eds.). Venom \& Toxin Research Group. Singapure.

Vellard, J. y Huidobro, F. 1941. Acción comparada de diversos venenos de oridios sobre la presión arterial. Rev. Soc. Argent. Biol. 17, 72.
Vidal, J. C. and Stoppani, A. O. M. 1971. Isolation and purification of two phospholipases $\mathrm{A}_{2}$ from Bothrops venoms. Arch. Biochem. Biophys 145, 543-556.

Vidal, J. C.; Cattaneo, P. and Stoppani, A. O. M. 1972. Some characteristic properties of phospholipase $\mathrm{A}_{2}$ from Bothrops neuwiedi. Arch. Biochem. Biophys $151,168$.

Worthington Biochemical Corporation. 1977. L-Amino Acid oxidase. The Worthington Manual Enzymes reagent related biochemicals, New Yersey, 49 .

Yarlequé, M. 1987. Estudio comparativo de algunas propiedades bioquímicas en los venenos de las serpientes de las familias: Crotalidae. Viperidae y Elapidae. Tesis para optar el grado académico de Bachiller en Ciencias Biológicas, Universidad Ricardo Palma.

Yarlequé, A.; Cárdenas, J.; Escobar, E. and Gutiérrez, S. 1997. Some biochemical properties and antibacterial action of a L-aminoacid oxidase from Peruvian snake venoms. Toxicon 35, 489. 